OPEN ACCESS

Edited by:

Aviv M. Weinstein, Ariel University, Israel

Reviewed by: Anna Franceschini, Center for Addiction Medicine, Italy

Delin Sun,

Duke University, United States

*Correspondence:

Valentina Lorenzett

valentina.Iorenzetti@gmail.com

Specialty section:

This article was submitted to

Addictive Disorders,

a section of the journal

Frontiers in Psychiatry

Received: 03 February 2021 Accepted: 10 May 2021

Published: 17 June 2021

Citation:

Lorenzetti V, Takagi M, van Dalen Y,

Yücel $M$ and Solowij N (2021)

Investigating the Residual Effects

of Chronic Cannabis Use and

Abstinence on Verbal and Visuospatial

Learning.

Front. Psychiatry 12:663701. doi: 10.3389/fpsyt.2021.663701

\section{Investigating the Residual Effects of Chronic Cannabis Use and Abstinence on Verbal and Visuospatial Learning}

\author{
Valentina Lorenzetti ${ }^{1 *}$, Michael Takagi ${ }^{2}$, Yvonne van Dalen $^{3}$, Murat Yücel ${ }^{4}$ and \\ Nadia Solowij ${ }^{5}$ \\ ${ }^{1}$ Neuroscience of Addiction and Mental Health Program, Faculty of Health Sciences, Healthy Brain and Mind Research \\ Centre, School of Behavioural and Health Sciences, Australian Catholic University, Melbourne, VIC, Australia, ${ }^{2}$ Child \\ Neuropsychology Unit, Murdoch Children's Research Institute, Melbourne, VIC, Australia, ${ }^{3}$ Faculty of Science, University of \\ Amsterdam, Amsterdam, Netherlands, ${ }^{4}$ BrainPark, School of Psychological Sciences and Monash Biomedical Imaging \\ Facility, The Turner Institute for Brain and Mental Health, Monash University, Melbourne, VIC, Australia, ${ }^{5}$ School of \\ Psychology and Illawarra Health and Medical Research Institute, University of Wollongong, Wollongong, NSW, Australia
}

Rationale: Regular cannabis users have been shown to differ from non-using controls in learning performance. It is unclear if these differences are specific to distinct domains of learning (verbal, visuospatial), exacerbate with extent of cannabis exposure and dissipate with sustained abstinence.

Objective: This study examines different domains of learning (verbal, visuospatial) in current and abstaining cannabis users, and the role of chronicity of use.

Methods: In a cross-sectional design, we examined 127 psychiatrically healthy participants (65 female) with mean aged of 34 years. Of these, 69 individuals were current regular cannabis users (mean 15 years use), 12 were former cannabis users abstinent for $\sim 2.5$ yrs (after a mean of 16 years use), and 46 were non-cannabis using controls. Groups were compared on verbal learning performance assessed via the California Verbal Learning Test (CVLT-II) and for visuospatial learning measured with the Brown Location Test (BLT). We explored the association between CVLT/BLT performance and cannabis use levels in current and former users.

Results: Current cannabis use compared to non-use was associated with worse performance on select aspects of verbal learning (Long Delay Cued Recall) and of visuospatial learning (Retroactive Interference and LD Rotated Recall). Prolonged abstinence was associated with altered verbal learning but intact visuospatial learning. There were non-significant correlations between distinct cannabis use measures, age and learning in both current and former users.

Conclusions: Our findings suggest cannabis use status (current use, former use) affects different domains of learning (verbal and visuospatial) in a distinct fashion. These findings might be accounted for in the design of cognitive interventions aimed to support abstinence in cannabis users.

Keywords: cannabis (marijuana), verbal learning and memory, visuospatial learning, abstinence, tetrahydrocannabinol, California Verbal Learning Test-Second Edition, Brown learning test 


\section{INTRODUCTION}

Cannabis is the most widely used illicit substance globally (1) and its potency has doubled over the past decade $(2,3)$. These statistics are concerning as a substantial proportion of cannabis users consume it on a regular basis $(4,5)$ and a significant minority of people with regular use experience lower school attainment, depression, anxiety, psychosis, impulsecontrol disorders, suicidal ideation and addiction (6). While there is much to learn about the cognitive correlates of regular cannabis use, a growing body of research has produced increasing knowledge in this area.

One of the core features of regular cannabis use entails alteration of cognitive performance that last beyond acute intoxication, which is thought to reflect chronic residual effects of regular cannabis use (7-12). In particular, altered cognitive function in regular cannabis users affects the domains of learning and memory, which are critical for performing daily tasks, at school and at work (7-13). Therefore, learning and memory alterations in regular cannabis users may underscore lower academic attainment $(14,15)$ and occupational performance found in cannabis using samples $(16,17)$.

Poorer learning and memory performance have been documented in regular cannabis users in both verbal and visuospatial domains. Specifically, relative to controls, regular cannabis users have shown lower verbal learning and recall of words (7-12), lower recall and accuracy of visuospatial performance in a checkerboard test (18), and lower retrieval in the virtual Morris water maze task (19). There are some inconsistencies however, as some of the examined samples have not shown verbal/visuospatial learning and memory alterations, or alterations with small to moderate effect sizes $(10-12,18-$ 22). Replication studies in larger samples are required to validate and further examine the association between cannabis use and learning/memory performance, particularly for the visuospatial domain which has been examined by few studies to date.

The role of the extent of cannabis exposure on verbal/visuospatial learning and memory alterations is unclear. Evidence suggests that higher chronicity of use predicts worse verbal learning and memory performance (23-29). However, there is a lack of empirical studies that tested in detail how distinct measures of cannabis exposure affect verbal/visuospatial learning. Such measures include: dosage, duration, age of use onset, hours from last use, potency $(9,10,12,30)$ and cannabinoids such as the main psychoactive compound $\Delta^{9}$ tetrahydrocannabinol (THC) that determines cannabis potency (31-33). The lack of studies on how cannabis use patterns and THC levels affect learning performance in chronic users, creates a knowledge gap to inform users, educators, clinicians and policy makers about which measures and levels of cannabis exposure may be more harmful for verbal/visuospatial learning in chronic cannabis users.

Another issue yet to be elucidated is whether poorer verbal/visuospatial learning performance in regular cannabis users persists beyond prolonged abstinence, and the relevant evidence to date is mixed. Some studies show that learning deficits persist beyond abstinence [i.e., after 1 month $(17,30)$ ].
Other studies found that learning alterations are attenuated (e.g., lower effect size) with longer abstinence (12) [e.g., over 4 to 8 weeks (34). Other studies show attenuated learning deficits in cannabis users who abstain for a variety of periods (11): 3 weeks (35), 1 month (36-40), 3 months (41)]; 12 months (35, 4246). The inconsistency between study findings may be due to methodological confounds, such as long-lasting residual effects of chronic exposure e.g., cumulative lifetime exposure prior to quitting (30).

In sum, lower verbal learning performance has been (largely) consistently identified in chronic, long-term cannabis users. However, visuospatial learning deficits are largely unexplored, as well as the role of cannabis exposure levels and of prolonged abstinence.

The primary aim of this study was to address this evidence gap and to examine whether current cannabis use is associated with selective impairment of either verbal or visuospatial learning and memory. We also aimed to explore the role of extent of cannabis exposure and of prolonged abstinence on verbal/visuospatial learning and memory in chronic cannabis users.

To do this, we recruited 127 people (65 females), consisting of 69 current users and 12 former cannabis users and 46 non-using controls, comprehensively characterized for extent of substance use (alcohol, tobacco and other illicit drug use; cannabis use frequency, quantity, duration, age of onset, time from last cannabis use) and mental health (anxiety, depression and psychotic symptoms). Based on the existing evidence, we hypothesized that worse verbal and visuospatial learning performance would be apparent in cannabis users with more chronic levels of exposure.

\section{MATERIALS AND METHODS}

\section{Participants}

We recruited 127 people aged between 18 and 55 years via advertisements in local newspapers and Internet websites, and screened using a structured telephone interview to determine study eligibility. Participants included 69 current chronic regular cannabis users, 12 former chronic cannabis users and 46 nonusing controls (henceforth called "current users," "former users," and "controls," respectively). All groups were age matched.

\section{Inclusion and Exclusion Criteria}

Cannabis users were included if they: (i) used cannabis at least twice a month for $>2$ years (the vast majority were currently using $>3$ days a week over many years, with a median of 30 smoking days/month and of 13 years of regular use); (ii) refrained from using substances other than cannabis, alcohol and tobacco in the month prior to assessment. Exclusion criteria for all participants were: (i) neurological disorders or serious head injury; (ii) Intelligence Quotient (IQ) <70; (iii) current regular use of illicit substances other than cannabis (amphetamines, benzodiazepines, cocaine, ecstasy, hallucinogens, inhalants and opiates; median lifetime use was between 0 and 6 occasions for any other drug).

All participants were requested to abstain from cannabis for at least $12 \mathrm{~h}$ prior to testing to enable examining cognitive 
function in a non-intoxicated state, and provided written informed consent in accordance with local ethics committee guidelines. Ethics approval was given by the Mental Health Research and Ethics Committee (MHREC, I.D. number 459111), the Melbourne Health and North Western Mental Health (Melbourne, Australia), the Wollongong Human Research Ethics Committee (HREC, project number NSA07/03), and the ethics committee of the Murdoch Children's Research Institute (MCRI).

\section{Procedure}

Participants underwent a comprehensive $2.5 \mathrm{~h}$ long assessment of mental health, substance use and cognitive function.

\section{Mental Health}

We screened for psychiatric disorders through the Structured Clinical Interview for the Diagnostic and Statistical Manual for Mental Disorders IV-R (47), and assessed global functioning via the Global Assessment of Functioning module of the DSMIV (48). We examined psychopathology symptoms of anxiety (State and Trait Anxiety Inventory, STAI; (49), depression and psychosis (Community Assessment of Psychic Experiences, CAPE (50).

\section{Substance Use}

We assessed lifetime and past month substance use through semi-structured interviews, including the Substance Use History [Orygen Youth Health Research Centre, Melbourne, Australia (51-53)], a detailed structured assessment interview for cannabis (27), and the Timeline Follow-Back (54). From these interviews, we derived levels of tobacco use (cigarettes per week) and cannabis use (i.e., lifetime and past year cumulative dosages and frequencies of use, duration of use and age of onset).

We converted cannabis dosage to standardized units (i.e., cones, approximately equivalent to $\sim 0.1 \mathrm{~g}$ ) (55). We measured urinary levels of the carboxy metabolite of THC (THC$\mathrm{COOH}$ ) via toxicology analysis, and THC accumulated in hair. Alcohol use (standard drinks per month) were quantified from the structured interviews and the Alcohol Use Disorders Identification Test (56).

\section{Cognitive Function}

We assessed current IQ, via the Wechsler Abbreviated Scale of Intelligence (WASI) (57) and premorbid IQ using the Wechsler Test of Adult Reading (WTAR) (58), respectively.

We measured verbal learning and memory via the California Verbal Learning Test, Second Edition (CVLT-II) (59), which was administered according to the manualized instructions. First, participants were asked to recall a list of 16 words presented orally (List A) for five consecutive trials (learning Trials 1 to 5). Then, participants were instructed to recall a new list of 16 words (List B). Subsequently, participants were asked to recall the words from List $A$ without any cues to aid memory, and then with cues (Short Delay Free Recall and Short Delay Cued Recall). After a 20 min interval, the latter procedure was repeated (Long Delay Free Recall and Long Delay Cued Recall). Finally, participants were asked if they recognized, from among a list of 48 words including distractors, those words that were previously presented in List A (Recognition Trial).

Visuospatial learning was examined using the Brown Location Test [BLT (60)], a visuospatial analog of the CVLT-type verbal learning tasks. Participants were presented with 12 pages, one at a time, on which 58 identically sized black outlined circles were located. At each presentation, one of the circles was filled with a red dot and the location of the red dot was different on each page, thus forming a "list" of 12 red dot-locations to remember akin to the list of words to be remembered on each trial of a verbal learning task. After each trial (i.e., the serial presentation of the 12 pages), the participant was provided an identical page of circles where none were filled with red, and was asked to place red chips in the locations where the red dots had been presented. This procedure was repeated 5 times (learning Trials 1 to 5).

Then, participants were presented with a new series of 12 black dots, which they were also asked to recall as above (Interference trial). Subsequently, participants were asked to recall the locations of the red dots from Trials 1-5 immediately after Interference (Short Delay Recall), after 20 min delay (Long Delay Recall), and after rotating the recall page 90 degrees. Finally, participants were presented with a page containing the original location of the red dots, and additional distractor red dots. Participants were asked to distinguish known 12 dot locations from 12 distractor dot locations (Recognition trial).

\section{Statistical Analyses Descriptive Demographic, Clinical, and Substance Use Data}

As the majority of variables were skewed and not transformable, group comparisons for descriptive purposes were performed using chi-square tests for categorical variables (sex); as well as ANCOVAs for normally distributed discrete variables (IQ, STAI) and Kruskal-Wallis tests, followed by post hoc Mann-Whitney U tests, for non-normally distributed discrete variables.

\section{Primary Aim}

To examine group differences for CVLT and BLT performance, Quade's method (61) was used for not normally distributed data from the CVLT and the BLT. Quade's method enables running non-parametric tests comparing groups using covariates. With Quade's method, the dependent variable in ANOVA is the unstandardized residual of a linear regression between the ranked (in ascending order) dependent variable (CVLT and BLT scores) and the ranked covariates (IQ for CVLT, IQ, and age for BLT).

Comparisons between CVLT and BLT trials within groups were performed using Friedman- and post-hoc Wilcoxon signed rank tests.

\section{Exploratory Correlations}

Spearman's correlations were run to investigate how performance on the CVLT and BLT (residualized data after regressing out the effects of IQ on the CVLT data, and that of IQ and age on the BLT data) was associated with (i) $\mathrm{THC}$ or $\mathrm{THC}-\mathrm{COOH}$ in hair and urine, respectively; and (ii) extent of cannabis use [duration, age at use onset, dosage (lifetime cumulative cones), frequency (smoking days/month), and hours since last cannabis use]. 
For all correlations, we utilized the conservative Bonferroni method to control for multiple tests and therefore readjusted the significance threshold to $\alpha=0.0005$.

\section{Covariates}

We retained IQ as a covariate in all analyses of CVLT and BLT data. We used age as an additional covariate in BLT data analyses, as age was significantly associated with BLT measures in non-users. Sex was used as a within-groups factor in analyses of CVLT but not BLT performance, as it significantly affected the former but not the latter. Alcohol standard drinks/month, tobacco cigarettes/week and sub-diagnostic psychopathology symptoms (i.e., anxiety, depression, positive and negative psychotic symptoms) were not included as covariates because they did not significantly affect CVLT and BLT performance.

\section{Sensitivity analyses}

A series of two sensitivity analyses were performed to confirm the robustness of the effects. First, all analyses were repeated excluding 12 chronic users who used any illicit substances other than cannabis and these confirmed the results from the analyses run with the whole sample. Therefore, we report the results from the whole group analyses.

Second, we reran group comparisons without 7 current users who on the day of testing admitted to having used cannabis for less than the required at least $12 \mathrm{~h}$-abstinence (range 3-10 h, median of $4 \mathrm{~h}$ ). As these individuals did not show overt signs of acute intoxication, we proceeded with testing.

All analyses were conducted using SPSS, Version 21 (IBM).

\section{RESULTS}

Table 1 summarizes data on demographic, clinical and substance use measures for chronic users, former users and non-users.

\section{Socio-Demographic and IQ Data}

All groups were matched by age and premorbid IQ. Chronic users and controls had an equal composition of males and females. However, former users had a lower proportion of females to males, relative to both chronic users $\left(\chi^{2}=5.82, p=0.016\right.$, respectively) and non-users $\left(\chi^{2}=6.05, p=0.014\right)$.

Education years were lower in chronic users than non-users $(\mathrm{Z}=-2.79, p=0.005)$, and IQ was also lower in chronic users than the other groups (i.e., controls $[\mathrm{t}=-3.71, p<0.001]$, former users [ $\mathrm{t}=-2.42, p=0.018]$ ). Global functioning was lower in both cannabis groups than controls (i.e., chronic users, $\mathrm{Z}=-6.96, p=<0.001$; and former users, $\mathrm{Z}=-3.80, p<0.001)$.

\section{Alcohol and tobacco Use level}

Alcohol use (standard drinks/month) was greater in former users compared to all groups (i.e., current users: $Z=-2.48$, $p=0.013$, and controls: $Z=-2.83, p=0.005)$. Tobacco use (cigarettes/week) was greater in current users than former users, and lowest in controls $(\mathrm{Z}=-2.13, p=0.034$ and $\mathrm{Z}=-3.24, p=$ 0.001 , respectively).

\section{Cannabis Use level}

The cannabis groups had similar cannabis use' duration, age of onset and lifetime dosage (see Table 1). However, current users smoked more days/week and consumed a greater amount of cannabis in the past year than former users.

Abstinence duration in current users was median of $16 \mathrm{~h}$ (range 3-336h). Seven current cannabis users reported abstaining for 3 to $10 \mathrm{~h}$ despite our request to abstain for at least $12 \mathrm{~h}$; and therefore analyses were repeated excluding these very recent users. Abstinence duration in former users was a mean of 2.5 years (median 6 months, range 1 month -19 years); 9 former users had ceased cannabis use within the past 12 months.

\section{Subclinical Psychopathology Symptoms}

Symptom severity for anxiety, depression and psychosis was greater in current users than controls $(\mathrm{t}=4.11, p<0.001$; $Z=-4.04, p=<0.001 ; Z=-2.66, p=0.008 ; Z=-3.41$, $p=0.001$, respectively), but did not differ between the other groups $(\mathrm{p}=$ n.s. $)$.

\section{Group Differences in CVLT Performance}

Table 1 Overviews group differences in CVLT performance. Group differences in CVLT trials are overviewed below, followed by learning curves and learning trials in each of the three groups (controls, current users, former users).

\section{CVLT Trials}

Group differences emerged for 7 out of the 18 CVLT variables: Trials 1, 3, 1-5, B, Short Delay Free Recall, Long Delay Free Recall and Long Delay Cued Recall (see Table 2).

\section{Current Users vs. Controls}

Cannabis users performed worse than controls for CVLT Trial 1 $(\mathrm{F}=6.52, p=0.012)$, and learning from Sum Trials $1-5(\mathrm{~F}=$ 4.54, $p=0.035)$. Additionally, current users recalled less words than controls for CVLT List B $(\mathrm{F}=10.08, p=0.002)$, Short Delay Free Recall ( $\mathrm{F}=4.37, p=0.039)$ and Long Delay Free Recall $(\mathrm{F}=5.12, p=0.026)$. These group differences did not survive a sensitivity analyses that we ran after excluding seven current users who consumed cannabis recently $<12$ h before testing.

After running the sensitivity analysis, the only performance difference that emerged in cannabis users vs. controls was poorer performance by users in Long Delay Cued Recall ( $\mathrm{F}=4.35$, $p=0.015)$.

\section{Former Users vs. Controls}

Similarly to current users, former users vs. controls showed lower CVLT performance for Long Delay Cued Recall ( $\mathrm{F}=4.42, p=$ $0.040)$, Trial $1(\mathrm{~F}=6.95, p=0.011)$, and learning from Sum Trials $1-5(\mathrm{~F}=5.14, p=0.027)$. Additionally, former users performed worse than controls on Trial $3(\mathrm{~F}=6.04, p=0.017)$.

\section{CVLT Learning Curves}

As shown in Figure 1, CVLT learning curves improved for all groups at every trial from Trial 1 to Trial 4 (all $p<0.001$ ). Controls improved word recall at every trial from Trial 1 to Trial ( $\mathrm{Z}$ range from -5.71 to $-4.54, p<0.001$ ). Similarly to controls, current users improved word recall at every trial from Trial 1 to 
TABLE 1 | Socio-demographic, cannabis and other substance use, and psychopathology symptoms current and former chronic cannabis users and controls.

\begin{tabular}{|c|c|c|c|c|c|c|c|}
\hline & & Controls & Cannabis users & Former cannabis users & $\mathbf{Z}$ & $p$ & df \\
\hline \multicolumn{8}{|c|}{ Socio-demographic, IQ, alcohol/tobacco } \\
\hline Total $N$ [female $]^{\dagger \ddagger}$ & & $46(26)$ & $69(37)$ & $12(2)$ & $x^{2} 6.53$ & 0.038 & 2 \\
\hline Age, yrs & & $31.17(12.83)$ & $32.68(11.17)$ & $37.83(11.03)$ & 3.34 & 0.188 & 126 \\
\hline Education, yrs* & & $13.97(1.60)$ & $12.82(2.25)$ & $13.17(2.41)$ & 7.90 & 0.019 & 122 \\
\hline Premorbid IQ & & $106.78(10.18)$ & $101.40(13.29)$ & $106.75(5.01)$ & 5.55 & 0.062 & 125 \\
\hline$I^{*} \ddagger$ & & $111.76(10.91)$ & $104.15(10.72)$ & $112.25(11.21)$ & 7.22 & 0.001 & 125 \\
\hline Global functioning ${ }^{*} \dagger$ & & $85.5(4.95)$ & $73.7(9.77)$ & $75.58(9.64)$ & 50.32 & $<0.001$ & 126 \\
\hline Alcohol use (drinks/mo $)^{\dagger \ddagger}$ & & $18.49(23.89)$ & $24.52(32.74)$ & $52.48(32.80)$ & 9.43 & 0.009 & 126 \\
\hline Tobacco (cigarettes/week) ${ }^{\star \dagger \ddagger}$ & & $4.95(16.79)$ & $58.95(53.15)$ & $29.33(38.16)$ & 56.56 & $<0.001$ & 126 \\
\hline \multicolumn{8}{|l|}{ Cannabis use } \\
\hline \multirow[t]{2}{*}{ Frequency, days/mo } & Lifetime $^{\ddagger}$ & NA & $23.24(6.89)$ & $28.83(4.04)$ & -3.63 & $<0.001$ & 80 \\
\hline & Past $12 \mathrm{mo}^{\ddagger}$ & NA & $24.59(8.62)$ & $3.33(8.51)$ & -4.81 & $<0.001$ & 80 \\
\hline \multirow[t]{2}{*}{ Dosage, cones } & Lifetime & NA & $69,183(73,271)$ & $43,036(36,492)$ & -1.17 & 0.241 & 80 \\
\hline & Past $12 \mathrm{mo}^{\ddagger}$ & NA & $5,070(4039)$ & $136.3(375.3)$ & -5.30 & $<0.001$ & 80 \\
\hline Duration of regular use, yrs & & NA & $15.13(10.00)$ & $15.92(9.61)$ & -0.297 & 0.767 & 80 \\
\hline Onset age, yrs & & NA & $16.96(3.93)$ & $17.33(3.75)$ & -0.510 & 0.610 & 80 \\
\hline Abstinence duration, yrs & & NA & NA & $2.46(5.56)$ & NA & NA & 12 \\
\hline \multicolumn{8}{|c|}{ Psychopathology symptom scores } \\
\hline Trait anxiety, STAI & & 33.64 (7.39) & $41.99(12.19)$ & $35.33(13.39)$ & 2.13 & 0.12 & 124 \\
\hline Depression, CAPE* & & $12.29(2.69)$ & $15.06(3.87)$ & $13.58(2.75)$ & 16.34 & $<0.001$ & 125 \\
\hline Positive psychotic, CAPE* & & $24.56(3.37)$ & $27.58(6.21)$ & $25.82(3.22)$ & 7.46 & 0.024 & 121 \\
\hline Negative psychotic, CAPE* & & $22.26(5.11)$ & $26.51(6.95)$ & $23.42(13.39)$ & 11.95 & 0.003 & 122 \\
\hline
\end{tabular}

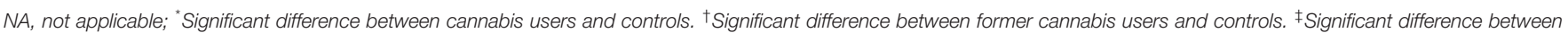

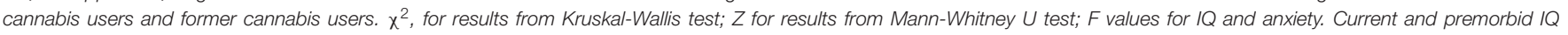

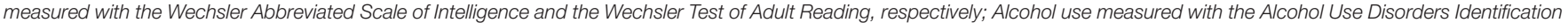

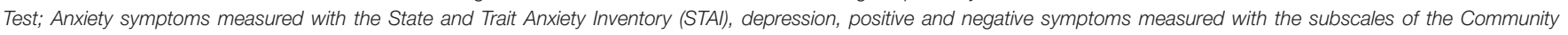
Assessment of Psychic Experiences (CAPE); Global functioning measured with the module of the DSM-IV.

Trial ( $\mathrm{Z}$ range from -6.83 to $-2.58, p<0.01$ ). Former users only significantly improved their word recall from Trial 1 to Trial 2 $(\mathrm{Z}=-3.08, p=0.002)$.

\section{CVLT Delayed Recall \\ Controls}

Controls showed a significant increase in the Long Delay Free Recall vs. Short Delay Free Recall $(Z=-3.09, p=0.002)$ and Long Delay Cued Recall vs. Short Delay Cued Recall $(Z=-3.25$, $p=0.001)$.

Additionally, controls improved significantly only after cues were given, in the Short Delay Cued Recall trial $(\mathrm{Z}=-2.14$, $p=0.032$ ).

\section{Current Users}

Similarly to controls, current users showed a significant increase in the Free Long Delay Recall vs. Free Short Delay Recall ( $\mathrm{Z}=$ -2.79, $p<0.005)$ and Cued Long Delay Recall vs. Cued Short Delay Recall $(\mathrm{Z}=-2.28, p=0.023)$. In contrast to controls, current users performed better during Cued Recall vs. Free Recall for the Short Delay trial $(Z=-3.06, p=0.002)$ and for the Long Delay trial $(\mathrm{Z}=-2.12, p=0.034)$.

\section{Former Users}

Former users did not show differences in any delayed recall trials.

\section{Exploratory Correlations Between CVLT Performance, Cannabis Use Measures, and Age}

Older age was not associated with any CVLT variables in cannabis users, but was associated with better recall at Trial 5 ( $\mathrm{rs}=0.465$, $p=0.001)$ and more Intrusions in controls ( $\mathrm{rs}=0.291, p=0.045)$ and with greater Recognition of False Positives in former users ( $\mathrm{rs}=0.602, p=0.029$ ).

\section{Current Users}

Greater cannabis frequency over the lifetime was associated with lower Retroactive Interference and greater Loss After Consolidation; and greater frequency of cannabis use in the past year was associated with worse recall at Trial 1. More cumulative cannabis dosage in the lifetime was correlated with worse recall at Trial 1 and worse Retroactive Interference; and greater past year cumulative dosage was correlated with worse recall at Trial 1. Earlier age of onset was correlated with less Intrusions, lower Retroactive Interference and greater Proactive Interference.

\section{Former Users}

In former users, greater frequency of cannabis use in the past year was associated with greater recall at Trial 1, greater Recognition of False Positives and lower Intrusions. Greater past year cumulative 
TABLE 2 | CVLT-II performance in current users, former users, and controls: mean (standard deviation).

\begin{tabular}{|c|c|c|c|c|c|c|}
\hline CVLT trials & Controls & Current users & Former users & F-value & $p$ & df \\
\hline Trial $1^{* \dagger}$ & $8.30(2.05)$ & $6.96(2.29)$ & $6.62(2.14)$ & 5.09 & 0.01 & 127 \\
\hline Trial 2 & $11.39(2.33)$ & $10.30(2.65)$ & $9.92(2.14)$ & 1.53 & 0.22 & 127 \\
\hline Trial 4 & $13.59(2.04)$ & $12.35(2.51)$ & $12.15(2.94)$ & 1.95 & 0.15 & 127 \\
\hline Trial 5 & $13.91(1.87)$ & $13.00(2.51)$ & $12.69(2.69)$ & 0.91 & 0.41 & 127 \\
\hline Short delay free recall* & $12.98(2.24)$ & $11.42(2.87)$ & $11.38(2.99)$ & 2.74 & 0.07 & 127 \\
\hline Short delay cued recall & $13.46(2.00)$ & $11.96(3.07)$ & $12.00(2.77)$ & 2.10 & 0.13 & 127 \\
\hline Long delay free recall* & $13.65(2.07)$ & $11.91(3.11)$ & $11.77(2.98)$ & 3.65 & 0.03 & 127 \\
\hline Long delay cued recall ${ }^{\dagger}$ & $13.87(1.89)$ & $12.28(2.95)$ & $11.77(3.11)$ & 3.35 & 0.04 & 127 \\
\hline Recognition & $15.28(0.958)$ & $14.67(1.50)$ & $15.38(0.961)$ & 2.14 & 0.12 & 127 \\
\hline Retroactive interference & $0.94(1.78)$ & $1.58(1.81)$ & $1.31(1.75)$ & 1.03 & 0.36 & 127 \\
\hline Loss after consolidation & $0.26(1.73)$ & $1.09(1.88)$ & $0.92(11.71)$ & 1.50 & 0.23 & 127 \\
\hline
\end{tabular}

"Significant difference between cannabis users and controls. ${ }^{\dagger}$ Significant difference between former cannabis users and controls. CVLT-II, California Verbal Learning Test Version 2. Proactive Interference, prior learning interfering with new learning (Trial 1- List B); Retroactive Interference, later learning interfering with previous learning (Trial 5-Short Delay Free Recall) and Loss after Consolidation, loss of recalled words after delay (Trial 5-Long Delay Free Recall).

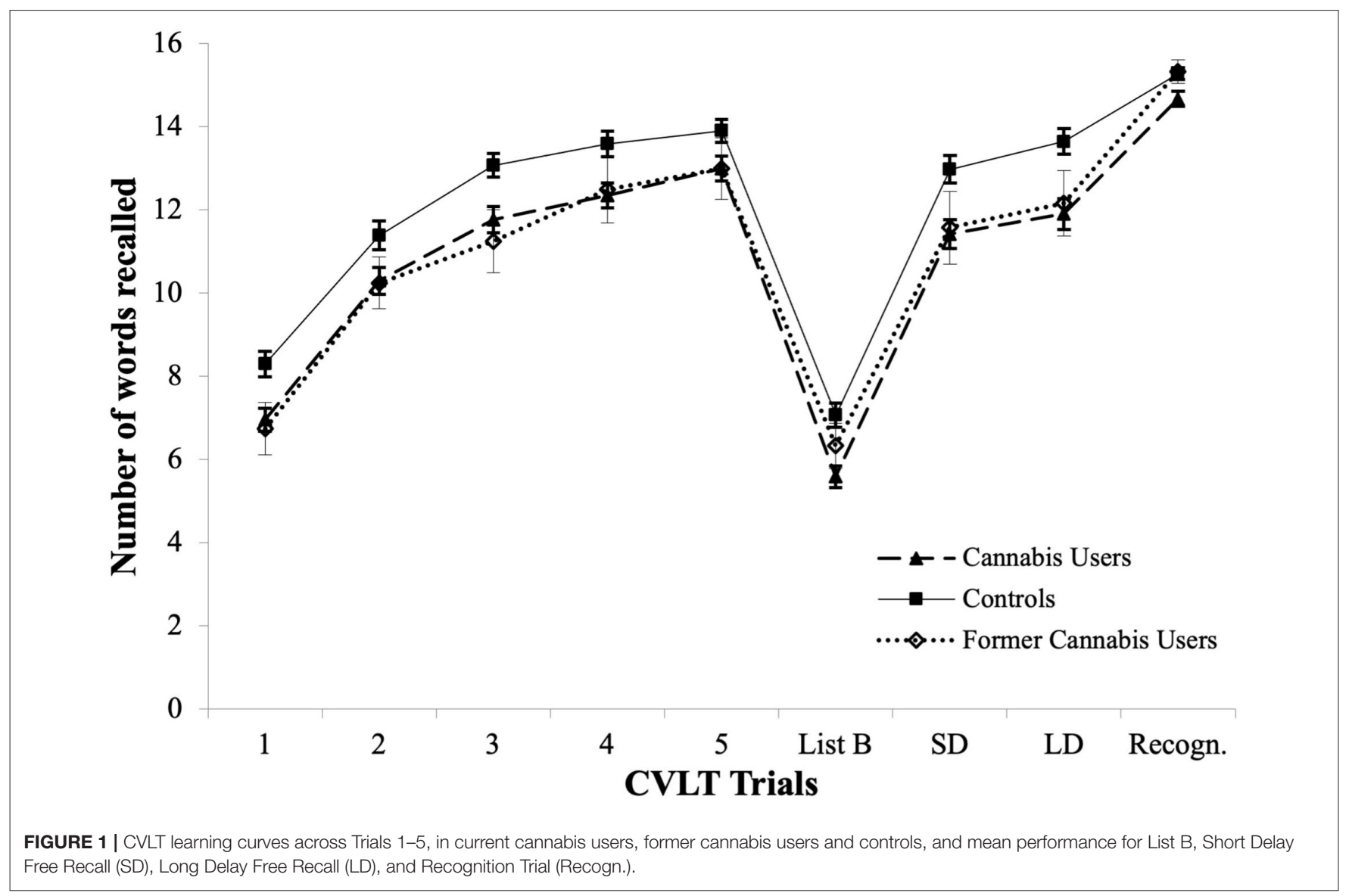


dosage was correlated with worse recall at Trial 4 . Earlier age of onset was correlated with better recall at Trials 1, 2, 3, 4, 1-5, and Trial $B$.

None of the correlations run between CVLT performance and cannabis use levels in current and former users survived Bonferroni correction for multiple tests (see Supplementary Tables 1, 2).

\section{Group Differences in BLT Performance BLT trials}

One cannabis user did not complete the BLT, hence for these analyses $n=68$ current cannabis users. BLT performance differed between groups for 2 of the 15 variables (see Table 3 ). Current users performed significantly worse than controls on Retroactive Interference and on Long Delay Rotated Recall (F = $5.95, p=0.016$ and $\mathrm{F}=1.62, p=0.014)$. Current users performed worse than former users on Short Delay Free Recall ( $\mathrm{F}=4.28, p$ $=0.042$ ).

\section{Sensitivity analyses for BLT trials}

After exclusion of seven participants who reported using cannabis within $12 \mathrm{~h}$ of the assessment, impaired performance persisted in current users vs. controls, for both Retroactive Interference $(\mathrm{F}=3.29, p=0.041)$ and Long Delay Rotated Recall $(\mathrm{F}=3.13, p=0.048)$.

\section{BLT learning curves}

BLT learning curves are shown in Figure 2. The pattern of results was identical to that of the CVLT: current users, former users and controls showed significant improvement in recall $\left[\chi_{(4,68)}^{2}=\right.$ 109.0, $p<0.001 ; \chi_{(4,12)}^{2}=24.89, p<0.001$ and $\chi_{(4,46)}^{2}=114.7$, $p<0.001$ respectively]. Current users and controls improved at every trial from Trial 1 to Trial 4 ( $\mathrm{Z}$ range between -4.38 and $-2.01, p<0.04$; and $Z$ range between -4.88 and -3.52 , $p<0.001$, respectively). Former cannabis users only improved between Trial 1 and Trial 2 (see learning curves in Figure 2, $\mathrm{Z}=$ $-2.57, p=0.010)$.

\section{BLT Delayed Recall}

Current users showed worse BLT performance in Delayed Recall only after Page Rotation ( $Z=-4.76, p<0.001)$. None of the groups showed a difference between Short Delay Recall and Long Delay Recall.

\section{Exploratory correlations Between BLT Performance, Age, and Cannabis Use Measures}

There was no association between age and BLT performance in neither current users, former users and controls.

\section{Current users}

In current cannabis users, greater lifetime cannabis use frequency was correlated with lower BLT recall at Trial 1-5 Total, and greater Recognition of False Positives. Greater THC-COOH in urine was associated with lower performance during Interference and better performance during the Proactive Interference trial.

\section{Former users}

In former cannabis users, greater frequency of cannabis use in the lifetime was associated with greater recall at BLT Trial 3, Trial 4, Trial 1-5 Total, Long Delay Free Recall, Long Delay Rotated Recall and greater Recognition Hits. Later age of cannabis use onset was associated with lower recall at Trial 3 and Trial 4, and lower Recognition Hits. Greater abstinence duration was associated with greater Long Delay Free Recall and Long Delay Rotated Recall.

None of the correlations between BLT performance, cannabis use levels and age in any groups survived Bonferroni correction for multiple tests (Supplementary Tables 3, 4).

\section{DISCUSSION}

This study shows that cannabis use status (current vs. former use) and extent of cannabinoid exposure have a differential impact on specific measures of verbal and visuospatial learning. Specifically, select measures of verbal learning in current and former cannabis users were impaired i.e., Long Delay Cued Recall of the CVLT. Instead, visuospatial learning was impaired only in current users i.e., Retroactive Interference and Long Delay Rotated Recall of the BLT. Performance on the CVLT and BLT was not significantly associated with any measures of cannabis exposure.

Poorer CVLT Long Delay Cued Recall performance in current cannabis users was robust to sensitivity analyses which excluded 7 people who did not appear intoxicated but admitted having smoked cannabis recently i.e., $<12 \mathrm{~h}$ before testing (instead of the required $>12 \mathrm{~h}$ ), and persisted in former users. Therefore, lower Long Delay Cued Recall may reflect the residual effects of chronic cannabis use that are long-lasting and detectable wellbeyond prolonged abstinence. This interpretation is consistent with findings that verbal learning alterations in cannabis users are apparent after THC metabolites are no longer detected in urine (9), and in cannabis users with chronic exposure reflected by long duration [i.e., 16 yrs (25) and 23 yrs (24)], dependent and almost daily use (62).

However, these notions are not supported by the lack of robust correlations between Long Delay Cued Recall and any measure of cannabis exposure including abstinence durations and chronicity of use. Therefore, the specific indices of cannabis exposure driving CVLT alterations in these groups of current and former users are unclear. Of note, verbal learning is ascribed by the function of posterior and frontoparietal cortices (41, 46, 63-65) that are high in cannabinoid receptors and thus might be vulnerable to the long lasting effects of repeated impact of cannabinoid exposure via complex neural mechanisms (66).

Surprisingly, most of the CVLT performance differences between current users and controls (i.e., Trial 1, Sum Trials 1-5, List B, Short Delay Free Recall, Long Delay Free Recall) were no longer detectable after sensitivity analyses without 7 people who recently smoked cannabis i.e., $<12 \mathrm{~h}$ before testing. Therefore, recent cannabis exposure may drive alterations of select components of verbal learning alterations (17, 24, 27, $41,46,62)$. This notion is supported by other study findings that better Ray Auditory Verbal Learning Test performance is associated with longer abstinence duration (67) (List B 
TABLE 3 | BLT performance in current cannabis users, former cannabis users and controls: mean (standard deviation).

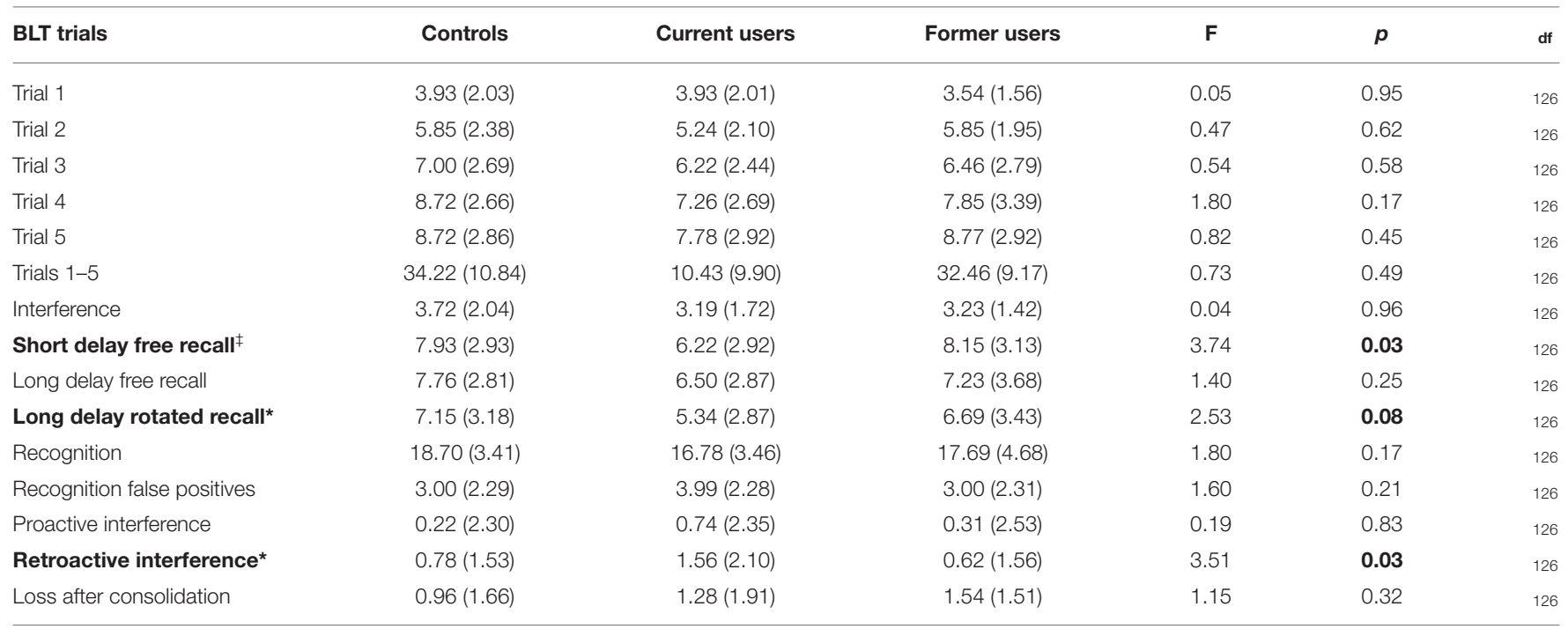

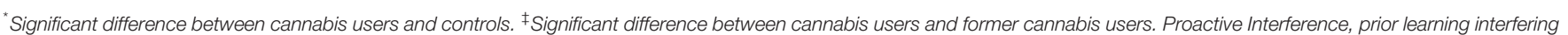

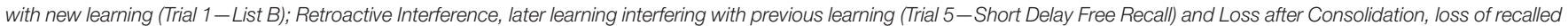
words after delay (Trial 5-Long Delay Free Recall).

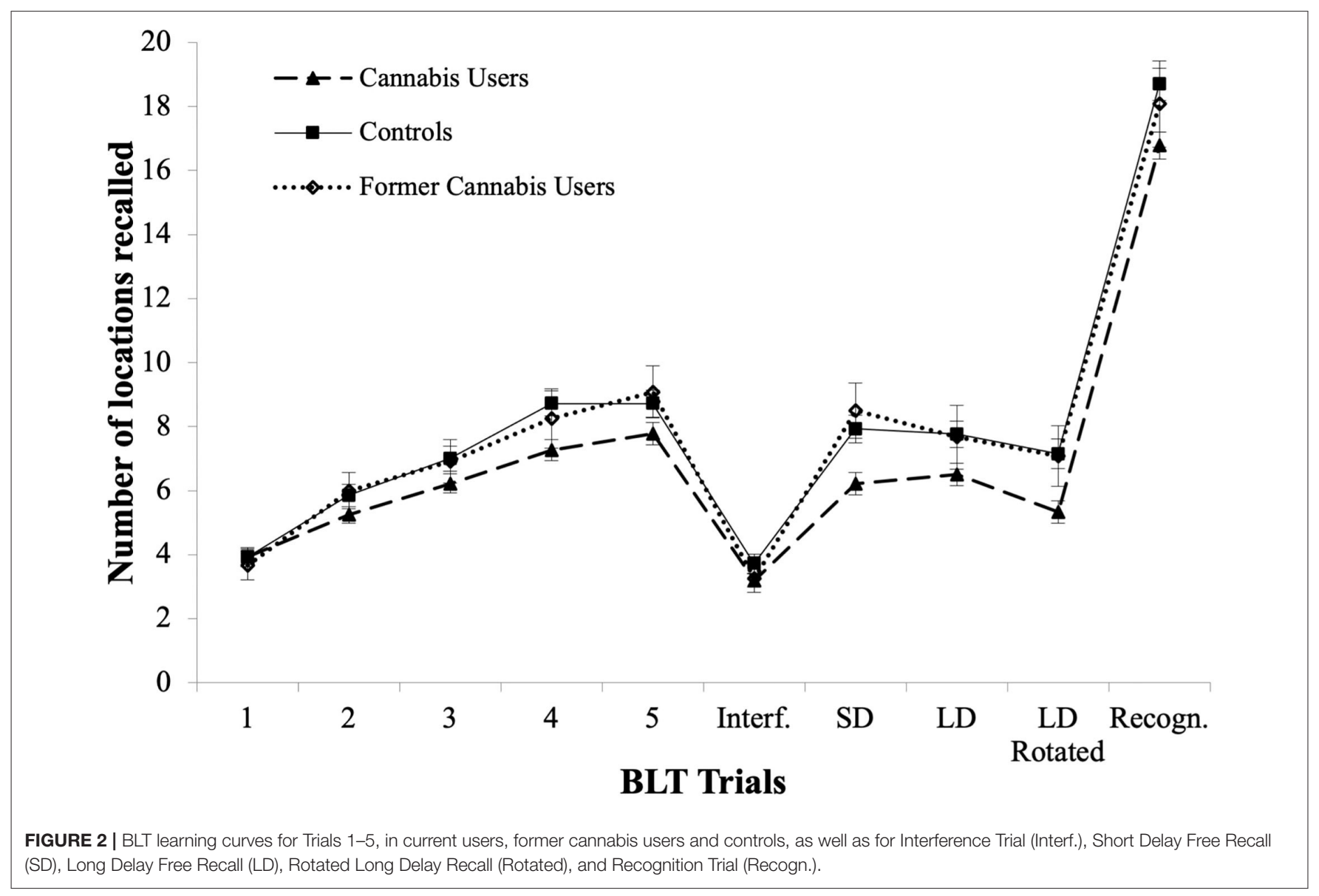

(27), total words recalled $(12,24)$. However, we found no significant correlation between better CVLT performance and number of hours from last cannabis use or urinary THC metabolites. Thus, the strength of this finding needs to be verified in future studies that carefully measure abstinence duration (68), as only a few studies of verbal learning to 
date report how long people abstained from cannabis before testing $(25,35)$.

Poorer visuospatial learning performance in cannabis users emerged in select BLT measures (Retroactive Interference and Long Delay Rotated Recall). These differences were robust and survived sensitivity analyses without a subgroup of recent users. Our findings are consistent with reports that visuospatial learning alterations in cannabis users affect recall but not acquisition trials $(19,45)$, but contrast previous meta-analytic findings that failed to find group differences (12).

The discrepancy between our results and those from previous work, might be due to systematic differences between sample characteristics and the tools used to assess visuospatial learning. First, our sample was older (i.e., 34 years) than the metaanalyzed samples i.e., <26 yrs (12). Interestingly, previous evidence shows that aging affects visuospatial learning (69-71). Therefore, lower visuospatial recall may be due to altered aging processes in cannabis users. However, the lack of significant correlations between age and BLT performance in this study does not support this notion and is to be further tested in future work. Second, the meta-analyzed studies to date used measures of visuospatial learning other than the BLT. Such measures (e.g., accuracy and total scores from the Rey-Osterrieth and Bender Visual-Motor Gestalt Test) might not have been sensitive enough to detect alterations specific to recall rather than acquisition trials (12).

The mechanisms underlying altered BLT in recall trials in current users are unclear. One candidate mechanism is impaired executive functioning $(45,72-74)$. Indeed, recallbut not acquisition-relies on executive function (75). Also, aging significantly affects the integrity of para-hippocampal and cingulate cortices that are concurrently ascribed to visuospatial learning, and to the residual effects of regular cannabis exposure (19).

Interestingly, we found for the first time that both current and former users showed similar Learning Curves across the verbal and visuospatial domains, suggesting the employment of common learning strategies across both domains (73). This similarity was apparent, given the similar structure of the BLT and the CVLT (i.e., both tests start with 5 Learning Trials, followed by an Interference trial and Delayed Recall trials). The overlapping learning curves between current and former users (see Figure 1), suggest that alteration of learning curves commences during regular use and does not recover after prolonged abstinence.

There are several limitations to this study. First, we examined a small sample of former users, and our findings require validation in larger samples. Second, our group of current users were not matched to controls for level of education, IQ and severity of subclinical psychopathology symptoms. Nevertheless, premorbid IQ was matched between groups, and we controlled for current IQ i.e., by using IQ as a covariate in all group comparisons (years of education were not associated with any performance measures and were thus not included as a covariate).

We also minimized potential confounding impact of severe mental health conditions on cognitive performance, by screening for any diagnoses of psychopathology. However, we cannot rule out that sub-clinical psychopathology symptoms in our sample, which are shown to exacerbate cognitive deficits (15), may have driven our findings on cognitive alterations. Since subclinical psychopathology symptoms as measured in this study did not exert a significant effect on performance, they were therefore not included as covariates in the analyses. On the other hand, our sample is representative of cannabis users within the general community, where higher (although not diagnosable) psychopathology symptoms and worse cognitive outcomes have been consistently reported (14, 76-79).

Third, correlational analyses were run in current users and former users including males and females, and not in different sexes separately, therefore precluding a detailed understanding of possible sex differences in the emerging alterations. Our strategy mitigated type-1 errors, as we have run a substantial number of correlational analyses in current and former cannabis users across all cognitive variables examined. Fourth, the number of abstinent users $(n=12)$ was small for statistical analyses, and findings pertaining to this group require replication in larger samples. Further, the cross-sectional study design and the lack of information on the sample' resilience levels, prevented to determine if abstinence was the reason for better performance compared to current usage, or the consequence of a latent factor such as resilience that also leads to better performance.

Our findings might be accounted for in the design of cognitive interventions aimed to support abstinence in cannabis users. For example, if a clinical practitioner knew that a patient uses cannabis regularly, and that regular cannabis use is associated with impaired Long Delay Cued Recall, the practitioner may implement strategies to ensure that their client recalls information/instructions critical for engaging with the treatment (e.g., repeating or asking the client to repeat the instruction/information, sharing written instructions). Also, knowing that regular cannabis users have worse performance on Retroactive Interference and LD Rotate Recall, could indicate to a practitioner that visuospatial information relevant for the treatment (e.g., the location of appointment/testing/treatment sites) may not be retained when learning occurs; and may prompt the practitioner to implement strategies to boost recall of visuospatial information relevant for the patient to attend treatment (e.g., sharing a map or sending a text reminder with information on appointment/testing/treatment sites).

In conclusion, our findings suggest that current cannabis use is associated with chronic residual effects on select aspects of verbal learning (Long Delay Cued Recall) and of visuospatial learning (Retroactive Interference and Long Delay Rotated Recall). Prolonged abstinence in former users was associated with altered verbal learning but intact visuospatial learning, suggesting that abstinence has a different impact on distinct domains of learning. Our findings warrant the conduct of future work that systematically tracks how learning performance in chronic cannabis users is affected during intoxication to map acute-onchronic effects, residual effects beyond intoxication, and those that remain with prolonged abstinence, to track how the residualon-chronic effects dissipate over time. Additional studies with careful assessment of cannabis use indices and exposure to THC and other cannabinoids, should examine how these findings 
extend to cannabis user groups who experience worse mental health outcomes.

\section{DATA AVAILABILITY STATEMENT}

The raw data supporting the conclusions of this article will be made available by the authors, without undue reservation.

\section{ETHICS STATEMENT}

Ethics approval was given by the Mental Health Research and Ethics Committee (MHREC, I.D. number 459111), the Melbourne Health and North Western Mental Health (Melbourne, Australia), the Wollongong Human Research Ethics Committee (HREC, project number NSA07/03), and the ethics committee of the Murdoch Children's Research Institute (MCRI). The patients/participants provided their written informed consent to participate in this study.

\section{AUTHOR CONTRIBUTIONS}

MT and VL drove data collection. VL drafted and revised the manuscript writing and statistical analyses and interpretation. YD contributed to the drafting and the running of the statistical analyses. MY and NS drove the study design. All authors

\section{REFERENCES}

1. UNODC. World Drug Report 2020. World Drug Report Series 2020. United Nations Office on Drugs and Crime (2020).

2. Chandra S, Radwan MM, Majumdar CG, Church JC, Freeman TP, ElSohly MA. New trends in cannabis potency in USA and Europe during the last decade (2008-2017). Eur Arch Psychiatry Clin Neurosci. (2019) 269:515. doi: 10.1007/s00406-019-00983-5

3. Freeman TP, Groshkova T, Cunningham A, Sedefov R, Griffiths P, Lynskey MT. Increasing potency and price of cannabis in Europe, 2006-16. Addiction. (2019) 114:1015-23. doi: 10.1111/add.14525

4. Budney AJ, Sofis MJ, Borodovsky JT. An update on cannabis use disorder with comment on the impact of policy related to therapeutic and recreational cannabis use. Eur Arch Psychiatry Clin Neurosci. (2019) 269:7386. doi: 10.1007/s00406-018-0976-1

5. Lopez-Quintero C, de los Cobos JP, Hasin DS, Okuda M, Wang A, Grant BF Blanco C. Probability and predictors of transition from first use to dependence on nicotine, alcohol, cannabis, and cocaine: results of the National Epidemiologic Survey on Alcohol and Related Conditions (NESARC). Drug Alcohol Depend. (2011) 115:120-30. doi: 10.1016/j.drugalcdep.2010.11.004

6. Lorenzetti V, Hoch E, Hall W. Adolescent cannabis use, cognition, brain health and educational outcomes: a review of the evidence. Eur Neuropsychopharmacol. (2020) 26:16980. doi: 10.1016/j.euroneuro.2020.03.012

7. Broyd SJ, van Hell HH, Beale C, Yücel M, Solowij N. Acute and chronic effects of cannabinoids on human cognition-a systematic review. Biol Psychiatry. (2016) 79:557-67. doi: 10.1016/j.biopsych.2015.12.002

8. Bogaty SER, Lee RSC, Hickie IB, Hermens DF. Meta-analysis of neurocognition in young psychosis patients with current cannabis use. $J$ Psychiatr Res. (2018) 99:22-32. doi: 10.1016/j.jpsychires.2018.01.010

9. Duperrouzel JC, Granja K, Pacheco-Colón I, Gonzalez R. Adverse effects of cannabis use on neurocognitive functioning: a systematic review of meta- analytic studies. J Dual Diagn. (2020) 16:43-57. doi: 10.1080/15504263.2019.1626030 revised the manuscript and contributed to the interpretation of the findings.

\section{FUNDING}

This study was funded by the National Medical \& Health Research Council (NHMRC ID: 459111). MY has received funding from Monash University, the National Health and Medical Research Council (NHMRC; including Fellowship \#APP1117188), the Australian Research Council (ARC), Australian Defence Science and Technology (DST), and the Department of Industry, Innovation and Science (DIIS). He has also received philanthropic donations from the David Winston Turner Endowment Fund, the Wilson Foundation, as well as payment from law firms in relation to court and/or expert witness reports. NS was supported by an Australian Research Council Future Fellowship (FT110100752). VL was supported by The Australian Catholic University through a competitive scheme.

\section{SUPPLEMENTARY MATERIAL}

The Supplementary Material for this article can be found online at: https://www.frontiersin.org/articles/10.3389/fpsyt. 2021.663701/full\#supplementary-material

10. Figueiredo PR, Tolomeo S, Steele JD, Baldacchino A. Neurocognitive consequences of chronic cannabis use: a systematic review and meta-analysis. Neurosci Biobehav Rev. (2020) 108:35869. doi: 10.1016/j.neubiorev.2019.10.014

11. Lovell ME, Akhurst J, Padgett C, Garry MI, Matthews A. Cognitive outcomes associated with long-term, regular, recreational cannabis use in adults: a meta-analysis. Exp Clin Psychopharmacol. (2020) 28:47194. doi: $10.1037 / \mathrm{pha} 0000326$

12. Scott JC, Wolf DH, Calkins ME, Bach EC, Weidner J, Ruparel K, et al. Cognitive functioning of adolescent and young adult cannabis users in the Philadelphia Neurodevelopmental Cohort. Psychol Addict Behav. (2017) 31:423-34. doi: 10.1037/adb0000268

13. Solowij N, Battisti R. The chronic effects of cannabis on memory in humans: a review. Curr Drug Abusers Rev. (2008) 1:81-98. doi: 10.2174/1874473710801010081

14. Volkow ND, Baler RD, Compton WM, Weiss SR. Adverse health effects of marijuana use. N Engl J Med. (2014) 370:221927. doi: 10.1056/NEJMra1402309

15. Farmer RF, Kosty DB, Seeley JR, Duncan SC, Lynskey MT, Rohde P, et al. Natural course of cannabis use disorders. Psychol Med. (2015) 45:6372. doi: 10.1017/S003329171400107X

16. Ellickson PL, Martino SC, Collins RL. Marijuana use from adolescence to young adulthood: multiple developmental trajectories and their associated outcomes. Health Psychol. (2004) 23:299-307. doi: 10.1037/0278-6133.23.3.299

17. Meier MH, Caspi A, Ambler A, Harrington H, Houts R, Keefe RS, et al. Persistent cannabis users show neuropsychological decline from childhood to midlife. Proc Natl Acad Sci USA. (2012) 109:E265764. doi: 10.1073/pnas.1206820109

18. Pope HG, Jacobs A, Mialet J-P, Yurgelun-Todd D, Gruber S. Evidence for a sex-specific residual effect of cannabis on visuospatial memory. Psychother Psychosom. (1997) 66:179-84. doi: 10.1159/000289132

19. Sneider JT, Gruber SA, Rogowska J, Silveri MM, Yurgelun-Todd DA. A preliminary study of functional brain activation among marijuana 
users during performance of a virtual water maze task. J Addict. (2013) 2013:461029. doi: 10.1155/2013/461029

20. Chang L, Yakupov R, Cloak C, Ernst T. Marijuana use is associated with a reorganized visual-attention network and cerebellar hypoactivation. Brain. (2006) 129:1096-12. doi: 10.1093/brain/awl064

21. Ashtari M, Avants B, Cyckowski L, Cervellione KL, Roofeh D, Cook P, et al. Medial temporal structures and memory functions in adolescents with heavy cannabis use. J Psychiatr Res. (2011) 45:1055-66. doi: 10.1016/j.jpsychires.2011.01.004

22. Gruber SA, Sagar KA, Dahlgren MK, Racine M, Lukas SE. Age of onset of marijuana use and executive function. Psychol Addict Behav. (2012) 26:496506. doi: $10.1037 / \mathrm{a} 0026269$

23. Solowij N, Stephens R, Roffman RA, Babor T. Does marijuana use cause long-term cognitive deficits? JAMA. (2002) 287:26534. doi: 10.1001/jama.287.9.1123

24. Solowij N, Stephens RS, Roffman RA, Babor T, Kadden R, Miller M, et al. Cognitive functioning of long-term heavy cannabis users seeking treatment. JAMA. (2002) 287:1123-31.

25. Messinis L, Kyprianidou A, Malefaki S, Papathanasopoulos P. Neuropsychological deficits in long-term frequent cannabis users. Neurology. (2006) 66:737-9. doi: 10.1212/01.wnl.0000201279.83203.c6

26. Becker B, Wagner D, Gouzoulis-Mayfrank E, Spuentrup E, Daumann, J. Altered parahippocampal functioning in cannabis users is related to the frequency of use. Psychopharmacology. (2010) 209:361-74. doi: 10.1007/s00213-010-1805-Z

27. Solowij N, Jones KA, Rozman ME, Davis SM, Ciarrochi J, Heaven PCL, et al. Verbal learning and memory in adolescent cannabis users, alcohol users and non-users. Psychopharmacology. (2011) 216:131-44. doi: 10.1007/s00213-011-2203-X

28. Cuttler C, McLaughlin RJ, Graf P. Mechanisms underlying the link between cannabis use and prospective memory. PloS ONE. (2012) 7:e36820. doi: 10.1371/journal.pone.0036820

29. Thames AD, Arbid N, Sayegh P. Cannabis use and neurocognitive functioning in a non-clinical sample of users. Addict Behav. (2014) 39:9949. doi: 10.1016/j.addbeh.2014.01.019

30. Bolla KI, Brown K, Eldreth D, Tate K, Cadet JL. Dose-related neurocognitive effects of marijuana use. Neurology. (2002) 59:1337-43. doi: 10.1212/01.WNL.0000031422.66442.49

31. Gaoni Y, Mechoulam R. The isolation and structure of delta-1tetrahydrocannabinol and other neutral cannabinoids from hashish. $J$ Am Chem Soc. (1971) 93:217-24. doi: 10.1021/ja00730a036

32. Landfield PW, Caldwallader LB, Vinsant S. Quantitative changes in hippocampal structure following long-term exposure to $\Delta 9$ tetrahydrocannabinol: possible mediation by glucocorticoid systems. Brain Res. (1988) 443:47-62. doi: 10.1016/0006-8993(88)91597-1

33. Di Forti M, Marconi A, Carra E, Fraietta S, Trotta A, Bonomo M, et al. Proportion of patients in south London with first-episode psychosis attributable to use of high potency cannabis: a case-control study. Lancet Psychiatry. (2015) 2:233-8. doi: 10.1016/S2215-0366(14)00117-5

34. Roten A, Baker NL, Gray KM. Cognitive performance in a placebo-controlled pharmacotherapy trial for youth with marijuana dependence. Addict Behav. (2015) 45:119-23. doi: 10.1016/j.addbeh.2015.01.013

35. Hanson KL, Winward JL, Schweinsburg AD, Medina KL, Brown SA, Tapert SF. Longitudinal study of cognition among adolescent marijuana users over three weeks of abstinence. Addict Behav. (2010) 35:9706. doi: 10.1016/j.addbeh.2010.06.012

36. Pope HG Jr, Gruber AJ, Hudson JI, Huestis MA, Yurgelun-Todd D. Neuropsychological performance in long-term cannabis users. Arch Gen Psychiatry. (2001) 58:909-15. doi: 10.1001/archpsyc.58.10.909

37. Medina KL, Nagel BJ, Park A, McQueeny T, Tapert SF. Depressive symptoms in adolescents: associations with white matter volume and marijuana use. J Child Psychol Psychiatry. (2007) 48:592600. doi: 10.1111/j.1469-7610.2007.01728.x

38. Medina KL, Schweinsburg AD, Cohen-Zion M, Nagel BJ, Tapert SF. Effects of alcohol and combined marijuana and alcohol use hippocampal volume and asymmetry. Neurotoxicol Teratol. (2007) 29:141-52. doi: 10.1016/j.ntt.2006.10.010
39. Schoeler T, Bhattacharyya S. The effect of cannabis use on memory function: an update. Subst Abuse Rehabil. (2013) 4:11. doi: 10.2147/SAR.S25869

40. Winward JL, Hanson KL, Tapert SF, Brown SA. Heavy alcohol use, marijuana use, and concomitant use by adolescents are associated with unique and shared cognitive decrements. J Int Neuropsychol Soc. (2014) 20:78495. doi: $10.1017 /$ S1355617714000666

41. Fried PA, Watkinson B, Gray R. Neurocognitive consequences of marihuanaa comparison with pre-drug performance. Neurotoxicol Teratol. (2005) 27:231-9. doi: 10.1016/j.ntt.2004.11.003

42. Lyons MJ, Bar JL, Panizzon MS, Toomey R, Eisen S, Xian H, et al. Neuropsychological consequences of regular marijuana use: a twin study. Psychol Med. (2004) 34:1239-50. doi: 10.1017/S0033291704002260

43. Solowij N. Do cognitive impairments recover following cessation of cannabis use? Life Sci. (1995) 56:2119-26. doi: 10.1016/0024-3205(95)00197-E

44. Medina KL, Hanson KL, Schweinsburg AD, Cohen-Zion M, Nagel BJ, Tapert SF. Neuropsychological functioning in adolescent marijuana users: subtle deficits detectable after a month of abstinence. J Int Neuropsychol Soc. (2007) 13:807-20. doi: 10.1017/S1355617707071032

45. McHale S, Hunt N. Executive function deficits in short-term abstinent cannabis users. Hum Psychopharmacol Clin Exp. (2008) 23:409-15. doi: 10.1002/hup.941

46. Tait RJ, Mackinnon A, Christensen H. Cannabis use and cognitive function: eight year trajectory in a young adult cohort. Addict Postprint. (2011) 106:2195-203. doi: 10.1111/j.1360-0443.2011.03574.x

47. American Psychiatric Association. DSM-V Diagnostic and Statistical Manual of Mental Disorders, 4th ed (2013).

48. American Psychiatric Association. DSM-IV Diagnostic and Statistical Manual of Mental Disorders, 4th ed (2006).

49. Spielberger CD. State-Trait Anxiety Inventory. John Wiley \& Sons, Inc. (2010).

50. Konings M, Bak M, Hanssen M, Van Os J, Krabbendam L. Validity and reliability of the CAPE: a self-report instrument for the measurement of psychotic experiences in the general population. Acta Psychiatr Scand. (2006) 114:55-61. doi: 10.1111/j.1600-0447.2005.00741.x

51. Yücel M, Zalesky A, Takagi MJ, Bora E, Fornito A, Ditchfield M, et al. Whitematter abnormalities in adolescents with long-term inhalant and cannabis use: a diffusion magnetic resonance imaging study. J Psychiatry Neurosci. (2010) 35:409-12. doi: 10.1503/jpn.090177

52. Takagi M, Lubman DI, Cotton S, Fornito A, Baliz Y, Tucker A, et al. Executive control among adolescent inhalant and cannabis users. Drug Alcohol Rev. (2011) 30:629-37. doi: 10.1111/j.1465-3362.2010.00256.x

53. Takagi M, Yücel M, Cotton SM, Baliz Y, Tucker A, Elkins $K$, et al. Verbal memory, learning, and executive functioning among adolescent inhalant and cannabis users. J Stud Alcohol Drugs. (2011) 72:96105. doi: 10.15288/jsad.2011.72.96

54. Sobell LC, Sobell MB. Timeline Follow-Back: A Technique for Assessing SelfReported Alcohol Consumption. Totowa, NJ: Humana Press (1992).

55. Lorenzetti $\mathrm{V}$. The association between cannabis use and human brain structure. [Ph.D. thesis]. Melbourne, VIC: The University of Melbourne (2012).

56. Bohn MJ, Babor TF, Kranzler HR. The alcohol use disorders identification test (AUDIT): validation of a screening instrument for use in medical settings. $J$ Stud Alcohol. (1995) 56:423-32. doi: 10.15288/jsa.1995.56.423

57. Wechsler D. Wechsler Adult Intelligence Scale, 3rd ed (1997).

58. Wechsler D. Manual for the Wechsler Test of Adult Reading (WTAR). San Antonio, TX: The Psychological Corporation (2001).

59. Delis DC, Kramer JH, Kaplan E, Ober B. The California Verbal Learning Test. San Antonio, TX (1987).

60. Brown FC, Roth RM, Saykin AJ, Beverly-Gibson G. A new measure of visual location learning and memory: development and psychometric properties for the Brown Location Test (BLT). Clin Neuropsychol. (2007) 21:81125. doi: 10.1080/13854040600878777

61. Quade D. Rank analysis of covariance. J Am Stat Assoc. (1967) 62:1187200. doi: 10.1080/01621459.1967.10500925

62. Roebke, PV, Vadhan NP, Brooks DP, Levin FR. Verbal learning in marijuana users seeking treatment: a comparison between depressed and non-depressed samples. Am J Drug Alcohol Abuse. (2014) 40:274-9. doi: 10.3109/00952990.2013.87 5551 
63. Pope HG Jr, Gruber AJ, Yurgelun-Todd D. Residual neuropsychologic effects of cannabis. Curr Psychiatry Rep. (2001) 3:50712. doi: 10.1007/s11920-001-0045-7

64. Ravizza SM, Delgado MR, Chein JM, Becker JT, Fiez JA. Functional dissociations within the inferior parietal cortex in verbal working memory. NeuroImage. (2004) 22:562-73. doi: 10.1016/j.neuroimage.2004.01.039

65. Jacobsen LK, Pugh KR, Constable RT, Westerveld M, Mencl WE. Functional correlates of verbal memory deficits emerging during nicotine withdrawal in abstinent adolescent cannabis users. Biol Psychiatry. (2007) 61:3140. doi: 10.1016/j.biopsych.2006.02.014

66. Jacobus J, Bava S, Cohen-Zion M, Mahmood O, Tapert S. Functional consequences of marijuana use in adolescents. Pharmacol Biochem Behav. (2009) 92:559-65. doi: 10.1016/j.pbb.2009.04.001

67. Rey A. L'examen psychologique dans les cas d'encéphalopathie traumatique(Les problems). Arch Psychol. (1941).

68. Harvey MA, Sellman JD, Porter RJ, Frampton CM. The relationship between non-acute adolescent cannabis use and cognition. Drug Alcohol Rev. (2007) 26:309-19. doi: 10.1080/09595230701247772

69. Bopp KL, Verhaeghen P. Age-related differences in control processes in verbal and visuospatial working memory: storage, transformation, supervision, and coordination. J Gerontol Ser B Psychol Sci Soc Sci. (2007) 62:P23946. doi: 10.1093/geronb/62.5.P239

70. Fiore F, Borella E, Mammarella IC, De Beni R. Age differences in verbal and visuo-spatial working memory updating: evidence from analysis of serial position curves. Memory. (2012) 20:1427. doi: 10.1080/09658211.2011.628320

71. Davis HP, Small SA, Stern Y, Mayeux R, Feldstein SN, Keller FR. Acquisition, recall, and forgetting of verbal information in long-term memory by young, middle-aged, and elderly individuals. Cortex. (2003) 39:106391. doi: 10.1016/S0010-9452(08)70878-5

72. Whitlow CT, Liguori A, Livengood LB, Hart SL, Mussat-Whitlow BJ, Lamborn CM, et al. Long-term heavy marijuana users make costly decisions on a gambling task. Drug Alcohol Depend. (2004) 76:10711. doi: 10.1016/j.drugalcdep.2004.04.009
73. Crean RD, Tapert SF, Minassian A, MacDonald K, Crane NA, Mason BJ. Effects of chronic, heavy cannabis use on executive functions. J Addict Med. (2011) 5:9. doi: 10.1097/ADM.0b013e31820c dd57

74. Montgomery C, Seddon A, Fisk J, Murphy PN, Jansari A. Cannabis-related deficits in real-world memory. Hum Psychopharmacol Clin Exp. (2012) 27:217-25. doi: 10.1002/hup.1273

75. Lundqvist T. Cognitive consequences of cannabis use: comparison with abuse of stimulants and heroin with regard to attention, memory and executive functions. Pharmacol Biochem Behav. (2005) 81:31930. doi: 10.1016/j.pbb.2005.02.017

76. Thomas H. A community survey of adverse effects of cannabis use. Drug Alcohol Depend. (1996) 42:201-7. doi: 10.1016/S0376-8716(96)01277-X

77. Troisi A, Pasini A, Saracco M, Spalletta G. Psychiatric symptoms in male cannabis users not using other illicit drugs. Addiction. (1998) 93:48792. doi: 10.1046/j.1360-0443.1998.9344874.x

78. Reilly D, Didcott P, Swift W, Hall W. Long-term cannabis use: characteristics of users in an Australian rural area. Addiction. (1998) 93:837-46. doi: 10.1046/j.1360-0443.1998.9368375.x

79. Patton GC, Coffey C, Carlin JB, Degenhardt L, Lynskey M, Hall W. Cannabis use and mental health in young people: cohort study. BMJ. (2002) 325:1195. doi: 10.1136/bmj.325.7374.1195

Conflict of Interest: The authors declare that the research was conducted in the absence of any commercial or financial relationships that could be construed as a potential conflict of interest.

Copyright (c) 2021 Lorenzetti, Takagi, van Dalen, Yücel and Solowij. This is an open-access article distributed under the terms of the Creative Commons Attribution License (CC BY). The use, distribution or reproduction in other forums is permitted, provided the original author(s) and the copyright owner(s) are credited and that the original publication in this journal is cited, in accordance with accepted academic practice. No use, distribution or reproduction is permitted which does not comply with these terms. 